E3S Web of Conferences 1, 05002 (2013)

DOI: $10.1051 /$ e3sconf/20130105002

(C) Owned by the authors, published by EDP Sciences, 2013

\title{
Characterization of trace metals in airborne carbonaceous aerosols by single-particle EDX - Scanning Electron Microscopy
}

\author{
$\underline{\text { A. Pietrodangelo }}^{1}$, S. Pareti $^{1}$ and C. Perrino ${ }^{1}$ \\ ${ }^{1}$ Institute for Atmospheric Pollution Research, National research Council (C.N.R.), Monterotondo (Rome), 00016, Italy \\ pietrodangelo@iia.cnr.it
}

\begin{abstract}
The presence of fine and ultrafine metal particles has been evidenced in size segregated airborne carbonaceous aerosols collected at one industrial and two background (urban and rural) sites during an extended field campaign in Central Italy. Analysis of the backscattered electrons (BSE) by SEM - EDX demonstrated an effective potential in evidencing main structural features of the metal content in identified carbon aerosols. Many observed ultrafine metal particles appear embedded in the skeleton of carbonaceous individual particles and aggregates in the coarse fraction, while the same is not evident in the case of mixed carbon-sulphates aerosol that has been detected in the submicron size. These carbon-sulphates formations include indeed nano-sized metal particles that appear physically combined but not embedded. Also, larger metal particles (ranging around $1 \mu \mathrm{m}$ physical size) were observed close to carbon materials, but not included in their structure. Main compositional differences of metal particles with size segregation could be evidenced by energy - dispersive $X$ ray spectrometry (EDX). Larger particles are mainly rich in Fe, frequently in presence of $\mathrm{Mn}, \mathrm{Cu}, \mathrm{Cr}$ and $\mathrm{Zn}$ in variable proportions; either oxidized or elemental metals were detected. On the other hand, ultrafine particles associated with carbon-sulphates aerosol are enriched in $\mathrm{Pb}$ and $\mathrm{Zn}$, although the presence of other trace elements not detectable by SEM - EDX technique cannot be excluded. Moreover, Ce-enriched ultrafine particles were clearly determined in cenospheres. Conversely, inclusion of fine and ultrafine metal particles was rarely or not observed in soot aggregates.
\end{abstract}

Key words: carbonaceous aerosol, trace metals, scanning electron microscopy, backscatter analysis

\section{Introduction}

Understanding trace metal levels in the atmosphere is critical in gaining knowledge of their global geochemical cycling and of their environmental and health impacts (Witt et al 2010). Transition metals enter the composition of Earth's crust and are thus commonly found in carbonaceous aerosols originated bv fossil fuels combustion and biomass burning processes (Popovicheva et al 2010; Hays et al 2009; Moffet et al 2008). Most metals (excluding $\mathrm{Hg}$ and few others) have low volatility at ambient conditions and hence are predominantly distributed in the particulate phase (Witt et al. 2010). Metal-containing particles are strongly implicated in noxious health effects of airborne PM (Moffet et al. 2008), depending on metal solubility and changing of oxidation state in biological fluids. Nevertheless, their physiological availability also relies on the chances of these particles of entering lungs as individual entities or as carried by other particles. Therefore, information on structural connections between metal particles and other airborne entities, e.g. carbonaceous aerosols, are critical in improving knowledge of metal activity in humans and animals. As a matter of fact, however, few works have been currently published which underline this issue, particularly referring to metal-containing particles linked to different types of carbon-rich aerosols (Utsunomiya et al. 2004; Sippula et al 2009; Hays et al 2009; Moffet et al 2008). It should be also noted that particulate metals embedded in the carbon formation could be easily not observable also by electron microscopy single particle analysis, unless certain techniques are employed, e.g. backscatter analysis (Hays et al. 2009). In this work, thus, the latter electron microscopy technique has been adopted to put on evidence main structural features of the linkage between metal particles and different types of carbonaceous particles collected at receptor sites.

\section{Materials and Methods}

Airborne PM was collected in parallel at three sites (one 
industrial and two background (urban and rural)) by 8-stage cascade impactors (Moudi 100) in Central Italy; 3 days and $24 \mathrm{~h}$ sampling was performed, respectively, for size fractions above and below $1 \mu \mathrm{m}$ aerodynamic diameter (a.d.). A Philips XL30 ESEM scanning electron microscope (FEI Company, tungsten filament) equipped with an energy dispersive spectrometer for $\mathrm{X}$ rays microanalysis (EDAX/AMETEK Inc., U.S.) was used for individual particle characterisation. About $8 \%$ of total filter area. was cut in the centre of polycarbonate membranes, fixed to aluminium stubs by self adhesive carbon discs (TAAB, 12mm Ø) and coated with an ultra-thin carbon layer by a vacuum evaporator (108 Carbon A, Cressington Scientific Instruments Ltd., U.K.), to provide sufficient electrical conductivity to minimize charge effects due to interaction with the electron beam. SEM EDX acquisitions were performed under high vacuum (10-6 $\mathrm{hPa})$ at $20 \mathrm{keV}$ accelerating voltage and WD $10 \mathrm{~mm}$. At least 500 individual particles per impactor stage were analysed.

\section{Results and Discussion}

Identified carbonaceous formations include char particles, soot single-chains and aggregates, cenospheres, carbon-with-secondary sulphates combined aerosol and silicon-rich carbonate particles. The use of backscatter analysis evidences the presence of metal particles included in each type of carbonaceous aerosol; conversely these particles are not evidenced by the respective secondary electron (SE) acquisition.

Char and soot aggregates, cenospheres and Si-rich carbonate particles are mostly observed in the $>1 \mu \mathrm{m}$ (a.d.) fraction, while mixed carbon-sulphates aerosol are mainly distributed in the finer fractions and are hardly distinguishable as single particles or aggregates, suggesting that they could be likely contributed by organics. Observed metal particles are in the $1-0.05 \mu \mathrm{m}$ physical size range, although the presence of smaller

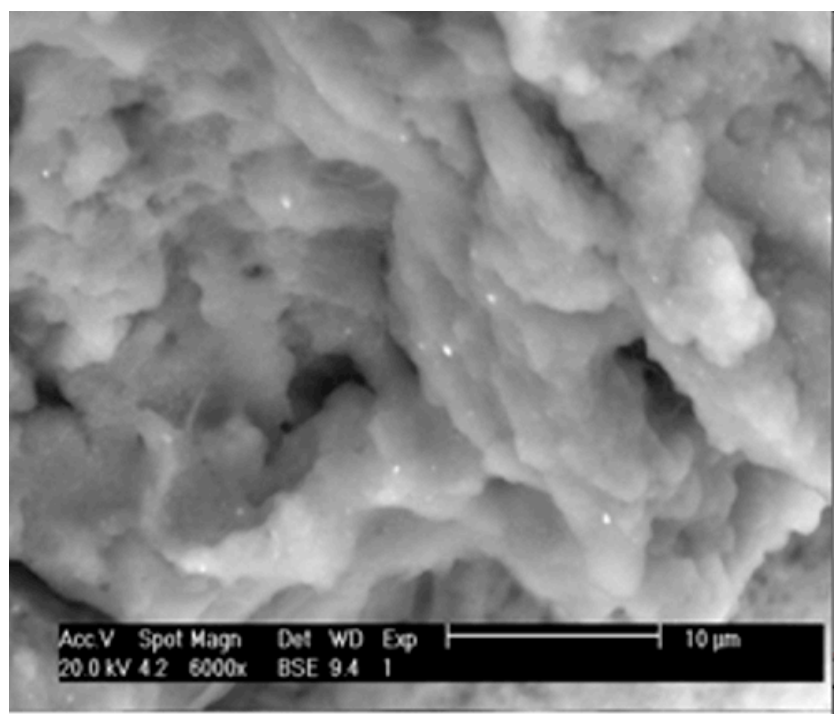

particles should be reasonably considered. Iron-rich particles are found in large number, showing rounded shape and average physical diameter ranging $0.8-1 \mu \mathrm{m}$. EDX spectra of smaller metal particles show $\mathrm{Fe}, \mathrm{Mn}, \mathrm{Cu}$, $\mathrm{Cr}$ and $\mathrm{Zn}$ in different proportion, with either rounded or elongated shapes. All these particles have been found associated mainly to char aggregates and Si-rich carbonate particles. The latter have been recovered in larger number at the industrial site, although they were also observed, in smaller proportion, at both background sites. The presence of $\mathrm{Pb}$, in some cases combined with $\mathrm{Zn}$, has been observed in a large number of nano-sized metal particles particularly identified in mixed carbon-sulphates materials (fig. 1), while these particles were not observed in char and Si-rich carbonate types. Moreover, EDX spectra put on evidence the presence of $\mathrm{Ni}, \mathrm{V}$ and $\mathrm{Ce}$ in nano-sized particles included in cenospheres (fig. 2). Conversely, no evidence of metal particles was generally observed in soot; nevertheless, metal particles, mostly Fe-rich and in the $0.8-1 \mu \mathrm{m}$ have been found included in the structure of large soot aggregates, mainly together with Si-rich particles (silicates and silica spheres) and inorganic salts.

\section{Conclusion}

Carbonaceous particles originated by different combustion processes have been identified in this study. These appear combined to metal particles in the ultrafine fraction. Main elemental composition and size of metal particles seem to overall differentiate with the various carbon aerosol types and also differences were observed in the way they are combined with carbon particles structure. Detecting these differences by single particle electron microscopy techniques could enhance knowledge on the role of combustion conditions in the metal enrichment of carbonaceous aerosols and on the role of the latter as carrier of metals in the respirable PM fraction.

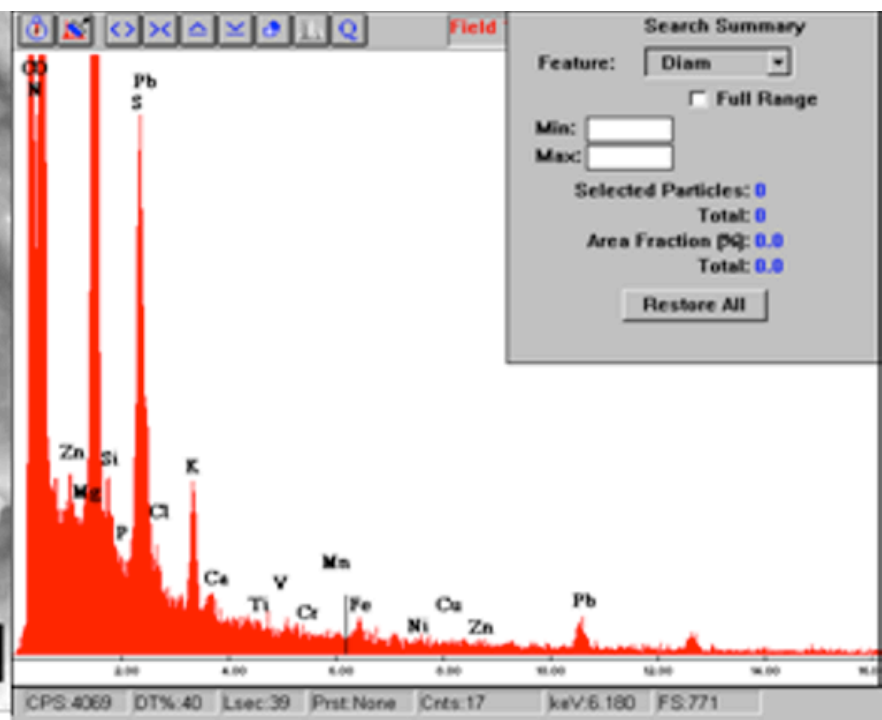

Fig. 1. Left: SEM micrograph of the carbon - sulphates mixed aerosol in the $0,32-0,18 \mu \mathrm{m}$ fraction, detected by the $\mathrm{BSE}$ signal. Internally included nano-sized metal particles are put on evidence. Right: EDX spectrum of a Pb-rich nanoparticle. 

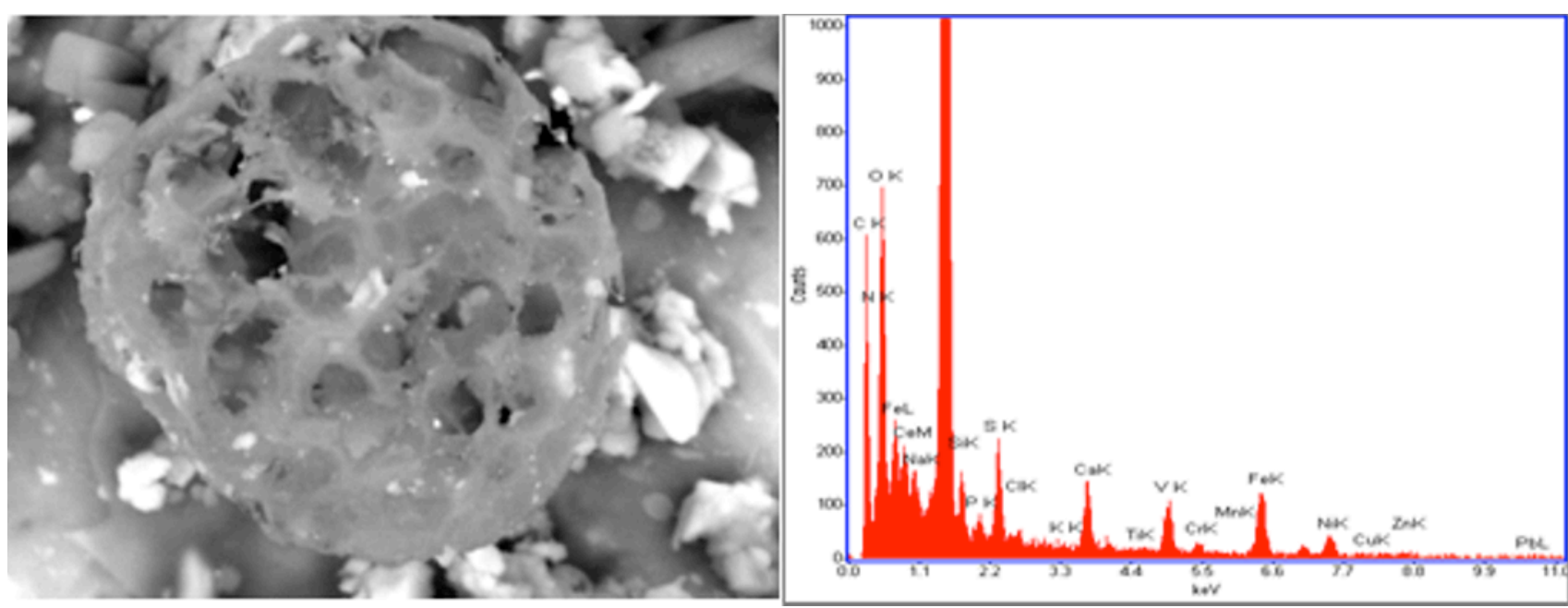

Fig. 2. Left: SEM micrograph of a cenosphere in the 3,2 - 5,6 $\mu \mathrm{m}$ fraction, detected by the BSE signal. Embedded nano-sized metal particles are put on evidence. Right: EDX spectrum of a nanoparticle containing $\mathrm{Ce}, \mathrm{V}$ and $\mathrm{Ni}$.

\section{Acknowledgements}

Thanks are due to stakeholders providing financial support to this study; details are confidential.

\section{References}

Hays MD, Beck L, et al. Physical and Chemical Characterization of Residual Oil-Fired Power Plant Emissions. Energy \& Fuels (2009);23: 2544-2551.

Moffet RC, Desyaterik Y, et al. Characterization of Aerosols Containing $\mathrm{Zn}, \mathrm{Pb}$, and $\mathrm{Cl}$ from an Industrial Region of Mexico City. Environ Sci Technol (2008);42: 7091-7097.
Popovicheva OB, Kireeva ED et al. Carbonaceous Aerosols of Aviation and Shipping Emissions. Atmos \& Ocean Phys (2010);46(3): 339-346.

Sippula O, Hokkinen J, et al. Comparison of particle emissions from small heavy fuel oil and wood-fired boilers. Atm Env (2009); 43:4855-4864.

Utsunomiya S, Jensen $\mathrm{K}$, et al. Direct Identification of Trace Metals in Fine and Ultrafine Particles in the Detroit Urban Atmosphere. Environ Sci Technol (2004);38: 2289-2297.

Witt MLI, Meheran N, Mather TA, De Hoog JCM, Pyle DM. Aerosol trace metals, particle morphology and total gaseous mercury in the atmosphere of Oxford, UK. Atm.Env.(2010);44:1524-1538. 